\title{
Ruth J. Dean, Anglo-Norman Literature. A Guide to Texts and Manuscripts
}

\section{G. Matteo Roccati}

\section{Q OpenEdition}

10 Journals

\section{Édition électronique}

URL : https://journals.openedition.org/studifrancesi/37126

DOI : 10.4000/studifrancesi.37126

ISSN : 2421-5856

Éditeur

Rosenberg \& Sellier

\section{Édition imprimée}

Date de publication : 15 décembre 2004

Pagination : 575

ISSN : 0039-2944

\section{Référence électronique}

G. Matteo Roccati, «Ruth J. Dean, Anglo-Norman Literature. A Guide to Texts and Manuscripts », Studi Francesi [En ligne], 144 (XLVIII | III) | 2004, mis en ligne le 30 novembre 2015, consulté le 08 mai 2021. URL : http://journals.openedition.org/studifrancesi/37126 ; DOI : https://doi.org/10.4000/ studifrancesi.37126

Ce document a été généré automatiquement le 8 mai 2021.

\section{(c)}

Studi Francesi è distribuita con Licenza Creative Commons Attribuzione - Non commerciale - Non opere derivate 4.0 Internazionale. 
Ruth J. Dean, Anglo-Norman

Literature. A Guide to Texts and

Manuscripts

G. Matteo Roccati 


\section{RÉFÉRENCE}

RUTH J. DEAN, with the collaboration of Maureen B. M. BOULTON, Anglo-Norman Literature. A Guide to Texts and Manuscripts, London, Anglo-Norman Text Society ("Occasional Publications Series", 3), 1999, pp. XVIII-554.

1 Le champ couvert par ce Guide est vaste, étant défini par des critères historiques et culturels, plus que strictement linguistiques: il comprend les oeuvres non seulement des auteurs anglo-normands, «but also English, Irish, and Continental ones, and some Continental French works known in England» (p. X). Sauf exception (lois de Guillaume le Conquérant, Magna Carta), il ne comprend pas la littérature juridique.

2 Le volume est organisé en deux grandes sections: Secular Literature (Historiographical, Lyric, Romance, Lais \& Fabliaux, Satirical, Social \& Moral, Proverbs, Grammar \& Glosses, Science \& Technology, Medicine) et Religious Literature (Biblical, Apocryphal, Hagiography, Homiletic, Devotional). Chaque oeuvre (dont de nombreux inédits) est identifiée par un numéro (près de mille items en tout, examinés dans plus de cinq cents manuscrits) et fait l'objet d'une notice. Celle-ci comporte une brève présentation, la reproduction de l'incipit (sur quelques lignes), le relevé des manuscrits (feuillets, particularités éventuelles, date de copie), l'indication des éditions et de la bibliographie (avec, le cas échéant, renvoi à des thèses lorsqu'il n'existe pas de publication et mention des compte-rendus utiles). Seuls ont été retenus les titres apportant des éléments intéressants pour la recherche. Le tout est complété par une série d'index: Concordance to Vising (1923, reimpr. 1972), Manuscripts, Incipits, Titles, Authors, Sources, Patrons.

Travail remarquable, réalisé avec soin et très riche. 